Now what would have been the proper reaction of a well-breath Athenian to a pip-squeak, upstart orator? Don't ask us: we cannot respond, for we have no record of how they reacted in Athens, Greece. However, we have a current, contemporary (1990) record of how they did react in Athens, Georgia or, for that matter, in Amsterdam, the Netherlands. Very recently, IGM Hans Ree, no mean player of Amsterdam, no mean city for all that, went on record on the behaviour of flesh-and-blood players when they saw computer chess cavorting. The humans chuckled with glee while silicon blustered and blundered.

Even so, Ree has to admit that "[m]eanwhile it cannot be denied that chess computers are getting results that a few years ago would be unthinkable." A grudging compliment, yet a compliment. And, of course, IGM Hans Ree will scoff at the claims of computer researchers: Weren't they financed by the Pentagon which also funds astrologers, dolphin researchers and self-styled clairvoyants?

Yet this scoffer is a champion of the wildest claims of computer chess. Far from denying that the future World Champion will be a program, he positively wishes for silicon to vanquish the human, for brawn to oust brain, "for then there would be no more reason to improve on the [computer-chess] program, since no one will notice this improvement ..."

Thank you, our hostile friend, for your learned and perceptive ridicule. At least you grant us, the international computer-chess community, the implicit victory: even in your vitw, sceptical resident of the Athens of the North, silicon will carry the day chippily, as it did, in a rather more pebbly way, with Demosthenes.

Your prediction has been noted and, chuckle as you may at the capers of the junior Demosthenes, we are glad you do not begrudge him the palm of victory in the end.

Welcome, unbeliever, to the band of the elect.

Bob Herschberg

Jaap van den Herik

Those willing to follow Hans Ree's reasoning more closely are referred to his August 1990 article in New in Chess, Vol. 7, No. 5, pp. 49-51.

\title{
LEVY LEAVES LOUDOUN
}

David Levy, the President of the ICCA, has changed front door, 'phone and fax. Will readers please note his address henceforth:

\author{
David N.L. Levy \\ 44, Aylestone Avenue \\ London NW6 7AA \\ England
}

Telephone: +44814592388

Fax: $\quad$ +44814596422 